\title{
Educaçáo como prática social com justiça social: um olhar criativo, complexo e transdisciplinar
}

\author{
João Henrique Suanno ${ }^{1}$ \\ https://orcid.org/0000-0003-0624-5378
}

\section{Resumo}

A relaçáo entre a educação e os processos educativos como uma prática social com a justiça social como intencionalidade do fazer pedagógico é o objetivo deste artigo. A necessidade de uma educaçáo que busque ensinar o exercício do pensar e, consequentemente, da reflexão sobre a sociedade em que cada um se insere, ou nasceu inserido, é visto aqui como um ideal da educação. Formar cidadãos está muito além do que formar pessoas obedientes que não são capazes de questionar a realidade e também incapazes de terem açóes propositivas de mudanças e transformaçóes da melhoria da qualidade de vida, tanto própria, quanto daqueles que lhes são caros, e aí, por que não falar da sociedade, da humanidade, do ser humano, se inserindo naquilo que lhe é mais caro: a sua vivência e a vivência da espécie humana. A educação tem um papel primordial na construção de cidadãos conscientes do seu papel questionador da realidade $\mathrm{e}$ transformador da sociedade. Entende, assim, que a escola, enquanto lócus da divulgação do legado intelectual da humanidade, também se compromete com a educação transformadora e libertadora de indivíduos, como verdadeiros cidadãos cônscios de direitos, deveres e responsabilidades para consigo e para seus semelhantes. Para tanto, nos amparamos em autores como Suanno, J (2012), Suanno, M. (2015, 2012), Suanno, J e Suanno, M. (2018), Suanno, J, Suanno, M e Torre (2014), D’Ambrosio (2013), Freire (2006, 2005, 2000), Hessel (2011), Moraes (2015), Moraes e Batalloso Navas (2020), Morin (2011), Pessoni Santos e Mendes Neto (2020) para ampliar a discussão e possibilitar ampliar o olhar para esta realidade.

Palavras-chave: Educação, Prática Social, Justiça Social, Criatividade, Complexidade.

\section{Education as social practice with social justice: a creative, complex and transdisciplinary look}

\section{Abstract}

The relationship between education and educational processes as a social practice with social justice as the intentionality of pedagogical practice is the objective of this article. The need for an education that seeks to teach the exercise of thinking and, consequently, reflection on the society in which each one is inserted, or was born inserted, is seen here as an ideal of education.

\footnotetext{
${ }^{1}$ Pós-Doutor em Educação pela Universidade de Barcelona - UB-ES. Doutor em Educação pela Universidade Católica de Brasília - UCB-DF. Mestre Educaçáo pela Universidad de La Habana-Cuba. Professo titular da Universidade Estadual de Goiás. Professor do quadro permanente do PPG-IELT/UEG e do PPGE/UEG. Editor Chefe da Revista Plurais - Anápolis-UEG. suanno@uol.com.br.
} 
Training citizens is much more than training obedient people who are not capable of questioning reality and also unable to take purposeful actions to change and transform the quality of life, both for themselves and for those who are dear to them. not to talk about society, humanity, human beings, inserting themselves in what is most dear to them: their experience and the experience of the human species. Education has a primary role in building citizens aware of their role in questioning reality and transforming society. Thus, it understands that the school, as the locus for the dissemination of the intellectual legacy of humanity, also commits itself to the transformative and liberating education of individuals, as true citizens aware of rights, duties and responsibilities towards themselves and their fellow men. To this end, we rely on authors such as Suanno, J (2012), Suanno, M. (2015, 2012), Suanno, J and Suanno, M. (2018), Suanno, J, Suanno, M and Toore (2014), D'Ambrosio (2013), Freire (2006, 2005, 2000), Hessel (2011), Moraes (2015), Moraes and Batalloso Navas (2020), Morin (2011), Pessoni Santos and Mendes Neto (2020) to expand the discussion and make it possible to broaden the view of this reality.

Keywords: Education, Social Practice, Social Justice, Creativity, Complexity.

\section{Introduçáo}

“não é possivel refazer este país, democratizá-lo, humanizá-lo, torná-lo sério, com adolescentes brincando de matar gente, ofendendo a vida, destruindo o sonho, inviabilizando o amor.

Se a educação sozinha não transformar a sociedade, sem ela tampouco a sociedade muda". Paulo Freire A Pedagogia da Indignação, 2000

O mais importante em uma sala de aula é que os alunos ampliem seus repertório, os alunos devem aprender, tem que acessar o conhecimento, os alunos têm que construir conhecimento. É ponto de preocupação quando o ensino apenas é aquele que acolhe, é afetivo e a pessoa sai vazia da relação educativa. É óbvio que temos que que acolher, sermos afetivos e amorosos, porém não são somente esses o papel do professor em sua responsabilidade com o ensino. A afetividade, a amorosidade e a acolhida é algo fundamental para estarmos juntos, também em processo de ensino e de aprendizagem, mas a atarefa do educador é educar! $\mathrm{O}$ aluno precisa aprender teorias, e a relação com o professor é um adendo importante para essa aprendizagem, mas não se encerra aí, pois dessa relação tem que ser produzida aprendizagens e, claro, a construção de conhecimentos pelo aluno. A tarefa da escola é que se socialize conhecimentos científicos, que os alunos aprendam a pensar crítico, que todos saibam buscar informaçóes em fontes fidedignas, verificando fontes e veracidade daquilo que lê, que lhe chega e que pensa em compartilhar. Como nos diz Moraes e Batalloso Navas (2020): 
Este carácter crítico de la Teoría de la Educación lógicamente está asociado a su finalidad práctica, porque educar es ante todo y sobre todo un hacer en, con, para los sujetos que se educan, por lo que exige continuas acciones y reflexiones de recreación, reconstrucción y reorientación. (p.72)

A verificação da fonte do conhecimento a ser acessado é de responsabilidade do professor e isso também é aprendido, então precisa ser ensinado em sala de aula aos nossos alunos. Isso é essencial para o desenvolvimento do pensamento crítico em via de mão dupla, ou seja, além de aprender a estabelecer critérios pessoais para saber se uma informação é verdadeira ou não, também há um zelo com o outro na preocupação que se tem com a responsabilidade daquilo que o professor, ou cada um de nós, apresentamos ao outro e aos conteúdos que, por meio de nós, entrarão em contato. A escola, dentro suas diversas funçóes sociais, precisa ampliar a nossa capacidade de reflexão e compreensão do mundo que nos cerca, desenvolvendo também o compromisso e o cuidado que devemos ter no meio social em que estamos inseridos. A criatividade se faz, aqui, presente quando buscar maneiras e estratégias de relacionar tantos conteúdos e elaborá-los de maneira que os alunos possam acessá-los contextualmente em suas realidades, na realidade local e global vivida por cada um e por todos, construindo sentidos e significados aos conteúdos apresentados pelo professor e sentidos por cada aluno em sala de aula.

Defender a prática pedagógica criativa, desta maneira, não significa o desenvolvimento de comportamentos mirabolantes, porém de estabelecer enfrentamentos às realidades adversas de maneira que possam ser vencidas, cada escola ao seu jeito. As práticas educacionais precisam ter como objetivos, além de socializar conhecimentos, promover a interação de alunos de diferentes idades, com classes sociais e integrando natureza, indivíduo e sociedade. Enquanto educadores, temos o compromisso e a responsabilidade de que nossas práticas pedagógicas sejam voltadas para a justiça social, com claro objetivo de contribuir na construçáo da paz, da dignidade humana que tem na justiça social, também, seus objetivos.

D’Ambrósio (2013) assim escreve sobre a relação da prática pedagógica, aliada à criatividade e à justiça social:

Aqui, eu elaboro sobre os propósitos da educação como preliminar para discutir o papel dos professores. Eu identifico um duplo propósito para o porquê das sociedades estabelecerem sistemas educacionais: 
1. Promover a cidadania (que prepara o indivíduo para estar integrado e produtivo na sociedade), obtida pela transmissão de valores e esclarecimento dos direitos e responsabilidades na sociedade.

2. Promover a criatividade (que leva ao progresso), obtida pela ajuda às pessoas a realizarem seus potenciais e ascenderem ao mais alto nível de sua capacidade. (p.15)

A educação, assim, também prepara aqueles que com ela se envolvem, com conhecimentos pertinentes, para o crescimento humano em valores, ética e justiça social quando seleciona saberes atuais e contextualizados. O crescimento humano, no sentido já dito, a partir da educação, é aquele que também possibilita a busca da liberdade de escolha, relaçôes sociais adequadas à saúde e bem-estar físico-emocional, respeito às escolhas alheias às suas, e que lhe proporcione tranquilidade, segurança e respeito. O professor, então, medeia o pensamento do aluno com a contextualização dos conteúdos e a realidade sentida e vivida por cada um daqueles que compartilham o ambiente de aprendizagem da sala de aula, sendo dentro ou fora dela.

Uma proposta de ensino transdisciplinar procura religar conhecimentos, culturas diversas, dentre elas a cultura das humanidades com a cultura científica, ou seja, a cultura das humanidades gera uma reflexão com base no pensamento do senso comum ou científico. Ao se falar de humanidades, não há a intenção de abarcar somente as áreas científicas representadas pelo termo, como a Psicologia, a Filosofia, a Antropologia, a Sociologia, a Pedagogia, o Direito, a Literatura, a História, as Artes e outras tantas, mas também de acessar o que de humano há e como nos encontramos representados em cada uma delas. A área de humanidades, assim se faz porque trazem um olhar específico de cada uma dessas ciências para movimentos e realizaçóes culturais dos povos ao redor do mundo e suas manifestaçóes de oralidade, escrita, grafismos, corpo e danças, além das manifestaçóes visuais, musicais e estéticas, sensíveis a cada povo e região, próprias e arraigadas em suas tradiçóes e que, em si, estabelecem representaçóes de lugares e maneiras de ser de povos ao redor do mundo.

A escola tem, então, o papel de realizar a cultura da religação, da reflexão, da sistematização, assim, não cabe somente apresentar esses conteúdos e lugares como existentes no mundo, isso é muito interessante, mas o papel da escola é ensinar, por meio da religação de saberes, os contextos ali vividos e sentidos, suas relaçóes com o entorno local, regional, nacional e global, a responsabilidade de cada povo no contexto do mundo em que vivemos, além da beleza e peculiaridades que cada um deles tem enquanto 
produtora de conhecimentos específicos. Daí podemos perceber que a escola não se resume em tratar de conhecimentos especificamente científicos, já que no legado da humanidade e na sua construção de conhecimentos cabem todos aqueles construídos por meio de todos os saberes acumulados em milênios de relação com a natureza e com os outros seres humanos e suas culturas.

O ensino que busca a relação entre áreas diversas e a aprendizagem de que todas estão acessíveis e são igualmente importantes para a compreensão do mundo e das relaçóes das pessoas com as outras, amplia a capacidade dos alunos a níveis de percepção de suas realidades pessoais, sociais e globais, além das suas relaçốes com as pessoas e comunidades às quais pertencem, além de contribuir para a busca de soluçóes problemas, de forma criativa, para as demandas que se lhes surgirão ao decorrer da vida de cada um. É contribuir para a autonomia, para a liberdade e autoria de suas açôes e participaçôes com responsabilidade social no mundo onde habitam. É aprender que a convivência social acontece em meio à diversidade de pensamentos, açóes, sentimentos, formas e, principalmente, concepçóes, entendendo que cada pessoa tem o direito de ser, pensar, sentir e agir como queira, assumindo a responsabilidade sobre cada uma dessas açôes.

As açôes de cada pessoa precisam ser resultadas de reflexóes religadas de saberes de maneira multidimensional, ou seja, analisadas as diversas influências para a existência de um fenômeno, os diversos elementos motivados da ação analisada, mesmo que contraditórios, e até necessário mesmo que assim o seja, mesmo que discordantes da minha própria forma de pensar, a fim de ampliar as possibilidades de olhares diversos buscando a sua compreensão. Isso também é ensinado, e pode o ser na escola! De fato, poderia dizer que deve ser ensinado na escola partindo do pressuposto da dúvida de que em que outro lugar aprenderíamos a fazer isso... O fazer pelo fazer não representa reflexão anterior que leva a uma organização de motivos e ações para a feitura, há que se pensar, há que se buscar a inspiração no desejo de execução de algo que se intenciona. Essa é a diferença entre ser um produtor ou ser um reprodutor de algo, e náo precisamos da escola para a segunda opção! Segundo Suanno, J, Suanno, M e Torre (2014),

Uma escola baseada em processos de aprendizagem a partir de vivência de práticas democráticas, dialógicas e de fruição estética. Pautada em valores humanos, solidariedade, responsabilidade social, responsabilidade ambiental, autonomia, igualdade, justiça social, direitos humanos, liberdade de expressão, democracia, ética, 
convivência harmoniosa, que favoreçam o desenvolvimento de uma consciência interior. (p.27)

Essa escola que se preocupa com os processos de aprendizagem dos alunos tem seu papel emancipador justamente na aprendizagem, pelos alunos, da sua capacidade de pensar, de refletir, de relacionar, de religar e isso se dá por meio do exercício do pensar com liberdade de expor seus pensamentos, de ter direito à voz para contar sobre o que pensou, sobre as relaçóes mentais que fez, os sentidos por eles encontrados, contribuindo para que se sintam pertencentes ao mundo, donos de seus pensares, autores de suas açóes, responsáveis por cada uma delas e com capacidade argumentativa de defendêlas.

A escola, desde muito antes da universidade e seu papel formador, tem a função da formação humana. Um ser humano formado assim, emancipado e com autonomia, chega à sua formação profissional capaz de avançar nas pesquisas, na busca de conteúdos, na organização de trabalhos, nas relaçóes interpessoais e de contribuir consigo mesmo, com os colegas e com os professores, por meio de sua capacidade de diálogo, interlocução, interpretação da realidade e análises em construção, com os momentos de ensino e de aprendizagem que ali acontecem e acontecerão. E não só aí, mas principalmente na vida que não se resume à escola ou à universidade. Assim, a escola contribui para o desenvolvimento de um pensamento que reflexiona e que questiona, e náo um pensamento que acata, repete, replica e não evoluciona para além do espaço limitado que, muitas vezes, sistemas e ideologias se nos impóem, citando aqui como exemplo exames em larga escala como a Provinha Brasil, Enem e Enad, assim como outras que também existem fora do contexto escolar. Desvelar a realidade é expô-la, sem as cortinas que guardam e escondem as intencionalidades, os objetivos, os mecanismos e maneirismos que, muitas vezes, senão na maioria delas, estão ocultos aos olhos e olhares daqueles que lhes são permitidos verem até onde lhes é oportunizado. E como meu aluno desvela essa realidade? Dando a ele a oportunidade o compreender e pensar o mundo problematizando-o, entendendo que existem opçóes outras que aquelas que se nos apresentam, procura as contradiçóes que estão sempre presentes em cada fato e em cada ação. Um ensino com base crítica, muitas vezes visto com maus olhos por uma boa parte da sociedade e diversas classes dentro dela, é um ensino que abre os olhares para o mundo, buscando desvelar o velado, o não permitido, o que está disfarçado rondando ao redor, as intencionalidades outras que aquelas contadas e isso liberta! E isso incomoda a quem não tem esses objetivos! Além 
de esse desvelar ser libertador para a sociedade! Assim, Moraes (2010), avança nesse tema e nos provoca com os seguintes questionamentos:

Quais são os problemas mais urgentes e as necessidades educacionais mais prementes de nosso contexto atual? Apesar do grande desenvolvimento científico e tecnológico, por que a civilização ocidental continua táo insensível ao subdesenvolvimento humano? Por que continuamos permitindo a expansão da geografia da fome, a explosão da pobreza e a falta de moradia e de condiçôes mínimas de trabalho? Por que o desenvolvimento material de nossa civilizaçáo continua provocando tanta degradaçáo meio-ambiental de natureza ecossistêmica? Por que somos cada vez mais individualistas e menos solidários? [...] (p. 1-2)

E aí nos voltamos para a responsabilidade da educação, não apenas essa, mas essa como mais uma delas, que é ensinar para humanizar a sociedade, e não ensinar para a desigualdade e competição. Humanizar parte da ideia de dar a condição humana, ou de humanar-se, ou seja, um retorno às suas características humanas, ou mesmo uma aquisição delas. Queremos ensinar para civilizar a sociedade, na busca de desenvolver a capacidade de sociabilidade aos nossos alunos, de adquirir um bom convívio social, de civilizarem-se.

Ainda inspirado pelas indagaçóes feitas por Moraes (2010), apresento outras questóes para pensarmos um pouco: educamos para individualizar ou para integrar a sociedade? Educamos para a fragmentação ou para a religação da sociedade? Educar para a individualidade é pensar em Justiça Social? Educamos para a igualdade ou para a compreensão da diversidade? As nossas intencionalidades, como educadores, são coletivas ou individuais? Estamos educando para o desenvolvimento de uma preocupação com o bem-estar do outro ou para o desenvolvimento do pensamento individualista? Nos preocupamos com o bem público e com o bem coletivo, e a sua manutenção na convivência humana? O que queremos com a educação de nossos filhos? $\mathrm{O}$ que desejamos com a formação dos nossos professores? A quem queremos ensinar? $\mathrm{O}$ que queremos ensinar? A quem atendemos quando planejamos o processo do ensino? O que queremos que nossos filhos/alunos aprendam? Com que objetivo? Essas perguntas não se esgotam aqui, senão que outras se nos passam pela cabeça e instigam respostas a serem buscadas.

Segundo Pessoni Santos e Mendes Neto (2020), 
São questóes que nos levam a pensar a urgência de um projeto educativo que seja capaz de gerar pessoas comprometidas com a vida em toda sua extensão. Um projeto que busque o pleno desenvolvimento do indivíduo, o respeito à pluralidade e diversidade dos seres, a efetivação da justiça social, a ampliação de atitudes solidárias e cooperativas, o respeito e conservaçáo aos bens naturais, o viver e conviver de forma harmoniosa. É preciso, portanto, problematizar o modo como a escola está organizada tanto em relação às suas concepçóes quanto suas práticas; entendendo que, cada dia mais, ela precisa ter uma conexão direta com a vida e com as demandas que sáo continuamente gestadas. (p.200)

Aqui podemos nos recorrer a Paulo Freire quando nos atenta a justiça social como uma das finalidades do processo educativo, e um dos caminhos é a indignação frente às injustiças sociais e a não proteção dos direitos fundamentais de todo cidadão. Isso é proteger a dignidade humana. Isso é se preocupar com as condiçóes sub-humanas na qual a sociedade, ou parte dela, se encontra, e se engajar no movimento de transformação social. $\mathrm{O}$ engajamento na causa social se inicia com a indignação contra essas condiçóes e na busca de dignidade para seus semelhantes, pessoas, cidadáos e seres humanos como todos, iguais nessa condição, primeira e primordial antes de outras que nos impóem pela discriminação a partir das diferenças, valorizando-as. A escola, nesse sentido, e por que não falar da educação, segundo Suanno,J (2012), afirma que

As crises pessoais, sociais, econômicas, políticas e outras, todas humanas, podem ser percebidas como uma grandiosa oportunidade para alavancar novas possibilidades de superaçáo da realidade atual, na melhoria que parte do pessoal, em primeiro lugar, para o social.

Criatividade e capacidade crítica aliadas no dia a dia são grandes diferenciais para o surgimento de açóes inovadoras, o que alteram a auto-imagem e o pensamento estratégico na busca de saídas de soluçóes problemas. (p.651)

A partir do exposto, vale nos remeter à Hessel (2011), quando nos diz que "o motivo da resistência é a indignação" (p. 15). Indignar-se é perceber a realidade vivida e não se acomodar com os absurdos estabelecidos como normais, como as diferenças sociais, a diferença de oportunidades de educaçáo, de trabalho, de melhoria da qualidade de vida para todos os cidadãos. Temos como experiência de cidadãos latino-americanos, e também europeus, de que mudanças sociais não costumam vir dos responsáveis 
políticos e econômicos, mas sim de manifestaçóes sociais que se indignaram a ponto de cobrar por seus direitos como membros de suas sociedades locais, e globais. Indignar-se, como diz esse autor, é precioso! A indignação seria como o fermento, literalmente biológico, que faz com que a massa, populacional, cresça em seus motivos de luta e resistência em favor de mudanças sociais que se atenham aos direitos primordiais dos seres humanos, cidadãos planetários. Suanno,M. (2012)

Hessel (2011) conclama que tenhamos motivos para indignação, pois esse é um valor precioso. $\mathrm{O}$ autor destaca que quando se tem algo com que se indignar, deve-se converte essa indignação em comprometimento e luta. Uma militância engajada e assim o cidadão passa a fazer parte de uma corrente da história e uma grande corrente deve seguir graças a cada um dos envolvido. $O$ autor faz um chamamento para que possamos lutar por direitos universais, como a Declaração Universal dos Direitos Humanos de 1948 e conclama que si encontrarmos com alguém que não se beneficia deles, que possamos nos compadecer e ajudar a conquistar. Compadecer, por tomar consciência e lutar em prol dos princípios democráticos, por direitos humanos, por conquistas sociais. (p.626)

A escola e o processo de ensino aí surgem nesse cenário, trazendo a religação da cultura da reflexão, da compreensão e da problematização do ser humano e da realidade, com uma outra cultura que é a cultura científica. E porque não, como nos traz Hessel (2011), também com a indignação, o que nos leva a entender aqui, cultura de problematização é a capacidade de fazer perguntas, indignando-se e questionando a realidade a fim de entendê-la multidimensionalmente e multirreferencialmente. A educação, nesse caso, contribui para que os alunos indaguem suas realidades na busca de transformaçôes pessoais e sociais, e não se conformem apenas em responder às questôes que lhe são feitas. A capacidade de problematização é um dos indicadores de saúde mental de uma população que procura saídas para as mazelas sentidas no seu cotidiano, desvelando os sentidos outros impregnados de ideologias outras que buscam a manutenção do silêncio social, na expectativa de que se mostrem apenas agradecidos diante das miseráveis doaçóes que recebem do sistema vigente, por serem lembrados por ele. Conforme Suanno,J e Suanno,M (2018),

A aceitação do pensamento divergente faz com que possam ser produzidas tantas ideias diferentes, quantas um indivíduo as possam 
ter, e trabalha com liberdade com o que lhe parece, em um primeiro momento, uma ideia improvável aparentemente. A evolução de seu pensamento, a partir de uma reflexão não linear, possibilita também uma quantidade maior de relaçóes circulares, em forma de rede, recebendo constantes contribuiçóes em relação ao que faz e refaz, buscando sempre novas alternativas que expliquem processos de autoorganização em sua estrutura de pensamento, sendo alimentado e retroalimentado pelos seus próprios resultados, sendo produto e, ao mesmo tempo, produtor de novas possibilidades. (p.134)

A fim de contribuir para que os alunos possam fazer esse exercício de reflexão, podemos lembrar de um dos ideais da educação, que é o desenvolvimento do bem pensar, levantando realidades vividas cotidianamente e ajudar os alunos/cidadãos a questionarem, como exemplo, o porquê de pagar, por meio de impostos, por serviços públicos de tão mal qualidade como o da saúde e, ao mesmo tempo, se angustiarem pela impossibilidade de pagar por serviços complementares, por exemplo, nessa área. Esse e outros tantos exemplos poderiam ser expostos em sala de aula, de forma que, se todos tivessem acesso a uma educação pública de qualidade, onde professores e funcionários públicos, valorizados, trabalhassem pelo bem comum, com remuneração, condiçóes de trabalho, reconhecimento social, com políticas públicas que lhes assegurem condiçóes dignas de trabalho e sobrevivência pessoal e familiar. E que não falássemos mais em sobrevivência, mas sim de vivências!

Desigualdades sociais e injustiças são perpetuadas por comportamentos de pessoas que não se percebem fazendo isso. Como exemplo podemos citar o valor pago por diversos tipos de serviços dentro de uma sociedade. Uma pessoa que paga, facilmente, o valor solicitado por um prato em um restaurante caro e, quando se encontra na frente de um artesão, negocia o valor pechinchando a ponto de não perceber que, assim, desvaloriza o trabalho daquele que tem pouco e vive de suas produçóes artesanais e manufaturadas. Ao fazer isso, a pessoa que pechincha não percebe que está a serviço de uma lógica que dita as diferenças e a discriminação entre as diversas classes sociais, e se coloca a serviço da manutenção da fragmentação social. Ainda trabalhando com essa ideia dos ideais da educação, aqui, a escola e as práticas docentes podem acontecer de forma a contribuir para que os alunos percebam fatos como esse. Assim, também, podem se identificar com a maioria da população que está, nesse exemplo, representada na segunda categoria.

Faz-se importante lembrar que cada escola guarda sua peculiaridade e que possuem certa autonomia do fazer pedagógico. Digo certa autonomia 
porque existem leis e planejamentos que precisam ser seguidos por todas, mas que não encerram completamente as formas de fazer e planejar o ensino dentro de cada escola. $\mathrm{O}$ acesso a esse tipo de informação e conteúdos, como ditos anteriormente, precisam ser tocados, discutidos e analisados com os alunos. Fica parecendo que tais conteúdos de análise crítica da sociedade e de suas relaçôes estre as pessoas, das mais diferentes classes sociais e organizativas, não são conteúdos a serem colocados em pauta nas aulas, e é em assuntos como esses que trazem o sentido do ensino, onde os alunos encontram o significado particular dos conteúdos, nas relaçôes que conseguem fazer espelhando a vida e a dos seus, nos conteúdos ministrados em sala de aula.

Edgar Morin (2011) traz que o conceito de vida precisa ser pensado a partir de três dimensóes. Quando fala da vida, não está falando de individualidade do indivíduo no que tange a sua vida como sendo afastada do todo, mas fala do ser que é, antes de tudo, individual sim, mas que também é sócio-político-econômico, além de ser, também, cultural, quando as diferentes culturas interferem no modo de ser, fazer e sentir de cada um, ou seja, interfere no modo de vida e na vida das pessoas. A relação com o processo de ensino, aqui, se dá na maneira em que proporcionamos oportunidades de problematização das diversas realidades e nos colocamos à disposição do exercício do pensar, da reflexão, da análise e da elaboração propositiva de ideias e construção de ideais onde a vida em sociedade possa ser pensada em função do melhor viver de todos, e um dos caminhos para isso é conceber a educação como uma articulação entre indivíduo, sociedade e cultura. Parece óbvio que o ensino se ocupe em trabalhar e com essa tríade indivíduosociedade-cultura, porém, uma questão a qual não podemos deixar de pensar são os ideais e as ideologias que regem cada maneira de fazer acontecer essa relação dentro de sala de aula. Por isso Morin (2011) propóe uma metamorfose antropológica que traga essa marca individual, cultural e sóciopolítica. Suanno,M. (2015), amplia esse olhar dizendo que:

Emerge uma educação humanizadora e complexa que intencionada ensinar: o diálogo; a compreensão; a diversidade cultural e a pluralidade dos indivíduos; a cidadania planetária; a dialógica democrática; a ética; a justiça social; a condição humana; o conhecimento pertinente e complexo, que seja crítico, histórico, social, ambiental e autopoiético; a capacidade de indignar-se e comprometerse com a transformação de si mesmo e do mundo; a formação do humano autônomo, emancipado, solidário, cooperativo e consciente. (p.43) 
O pensamento complexo contribui com essa questão, como não poderia deixar de ser, ampliando os limites da ciência moderna e os limites da racionalidade, que impulsionam os movimentos simplificadores da compreensão do mundo e do der humano, fazendo um movimento inverso à fragmentaçáo das diversas áreas da ciência que buscam, cada uma ao seu modo e dentro do seu olhar, a compreensão desse ser humano como se ele participasse efetivamente no mundo somente a partir do ponto de vista de cada área do conhecimento. Edgar Morin (2011) traz, para contribuir com essa discussão a noção, e um dos princípios organizadores do pensamento complexo, a noção de religação de saberes, entendendo que o movimento que a ciência fez em separar as áreas para compreender o ser humano, o fragmentou de tal forma que necessitamos juntar essas compreensóes, religando-as, pois esse não se representa como partes separadas de análise, mas que para ser compreendido, o deve ser feito a partir das relaçóes entre todas elas, pois uma só que não é levada em consideração, faz-se o comprometimento da compreensão do todo que ele é. Aqui, por último, falamos de outro princípio organizador do pensamento complexo, que é o hologramático. Fica claro assim, que o pensamento complexo não nega que existam tantas facetas para se realizar o entendimento do que é a individualidade e o ser humano, mas busca ir além dos limites da compreensão simplificadora da ciência moderna, visando sua superação, estando assim no campo das intencionalidades.

\section{Consideraçōes Provisórias}

Percebemos, assim, por mais que já temos visto tantos escritos acerca do papel da educaçáo, algumas problematizaçóes que intenciona novos, ou remodelados, questionamentos, mas todos atuais e necessários de reflexão e, principalmente, de açóes em função das necessidades que se expóem aos nossos sentidos, todos eles, e que nos tomam para além destes. Percebemos também que os processos educativos podem ter diversas funçóes em detrimento da ideologia que os anteveem, mas que podem ser libertadores de opressão e de mazelas sociais nos impostas por outrem que se preocupam mais com as individualidades que com a coletividade. Percebemos também que o compromisso dos educadores precisa estar voltado para o desenvolvimento pessoal, intelectual e social dos seus alunos, e que os processos e conteúdos precisam ser ministrados, ou melhor, dialogados no sentido de possibilitar a construção de um pensamento crítico, amplo, social e em torno da justiça. 
Em torno da justiça social é importante lembrar que não deve ser esperada de ninguém, porém que deve ser exercida e exercitada por todos, daí, quem sabe, a geração que está hoje na escola, possa ser essa a transformadora das diversas realidades sociais que se nos apresentarão nos próximos anos.

\section{Referências}

D'AMBROSIO, Ubiratan. Um sentido mais amplo de ensino da matemática para a justiça social. I Congreso de Educación Matemática de América Central y El Caribe. Santo Domingo, República Dominicana. 6 a 8 de novembro de 2013.

FREIRE, Paulo. Pedagogia da Autonomia: saberes necessários à prática educativa. 34 ed. São Paulo: Paz e Terra, 2006.

FREIRE, Paulo. Pedagogia do Oprimido. 42 ed. Rio de Janeiro: Paz e Terra, 2005.

FREIRE, Paulo. Pedagogia da Indignaçâo: cartas pedagógicas e outros escritos. São Paulo: Editora UNESP, 2000.

HESSEL, Stéphane. Indignai-vos! Tradução: Marli Peres. São Paulo: Leya, 2011.

MORAES, Maria Cândida. Didática Transdisciplinar como Expressão de uma Fenomenologia Complexa. Revista Inter-Legere. Revista do Programa de Pós-Graduação em Ciências Sociais da UFRN. Natal-RN, n.16, jan./jun. de 2015.

MORAES, Maria Cândida e BATALlOSO NAVAS, Juan Miguel. Contextualización educativa: ética, política y transdisciplinariedad. Revista Educação \& Linguagem. v. 23 n. 1. jan.-jun. 2020.

MORIN, Edgar. La Via: para el futuro de la humanidade. Impreso en Dedalo Offset, S. 1. Polígono Mateu-Cromo, Madrid - Espanha, 2011.

PESSONI SANTOS, Lindalva e MENDES NETO, Oscar Ferreira. As demandas da sociedade contemporânea e a urgência por uma formação cidadã. In: FREITAS, Carla Conti de Freitas, REIS, Marlene Barbosa de e OLIVEIRA, Daniel Júnior de (Org.). Formação de professores: possibilidades e demandas contemporâneas. Goiânia: Scotti, 2020. 
SUANNO, João Henrique. Creatividad y Adversidad: una oportuna articulación. In: V Congreso Internacional de Transdisciplinariedad, Complejidad y Ecoformación "Emergencia de una educación integral de calidad para la transformación social”. Barranquilla, Colômbia. Agosto 29, 30 y 31 de 2012.

SUANNO, João Henrique, SUANNO, Marilza Vanessa Rosa. Escola Criativa e Criatividade: saber, fazer e interagir. In: PEREIRA PINTO, Magda, SCHERRE, Paula Pereira (Org.). Escolas ecossistêmicas e complexas: Olhares para além da fragmentação. Global Knowledge Academics, Madri Espanha. 2018.

SUANNO, João Henrique, SUANNO, Marilza Vanessa Rosa; TORRE, Saturnino De La. Rede Internacional de Escolas Criativas. In: SUANNO, João Henrique, SUANNO, Marilza Vanessa Rosa, \& PINHO, Maria José de (Org.). Formação de Professores e interdisciplinaridade: diálogo investigativo em construção. V. único, p. 15-32. 1a ed. Goiânia: Editora América, 2014.

SUANNO, Marilza Vanessa Rosa. Fogo Prometeico, Reforma do Pensamento e o Redimensionar das Práticas Educativas: emergem perspectivas didáticas a partir da complexidade e da transdisciplinaridade. In: Dossiê ECOTRANSD: Ecologia dos saberes e Transdisciplinaridade. Revista Terceiro Incluído - UFG. ISSN 2237-079X. v.5, n.1, Jan./Jun., 2015.

SUANNO, Marilza Vanessa Rosa. Chamamentos contemporâneos e pensamento complexo: indignai-vos! Comprometei-vos! Reorganizai-vos! Reformai-vos! In: $V$ Congreso Internacional de Transdisciplinariedad, Complejidad y Ecoformación "Emergencia de una educación integral de calidad para la transformación social". Barranquilla, Colômbia. Agosto 29, 30 y 31 de 2012.

Recebido em: 01 set. 2020

Aceito em: $17 \mathrm{dez} .2020$ 